\title{
Новые жилые кварталы Еревана
}

\author{
Мартин Арутюнян, Институт искусств, Ереван, Армения
}

Начатые в 2010 году в Ереване широкомасштабные работы по строительству жилых зданий постепенно переместились в пригороды Еревана.

После обретения независимости в Армении отмечался всплеск строительства многоквартирных домов, что придало новое дыхание как градостроительству, так и экономике Армении, однако в то же время нарушило градостроительную и архитектурную среду Еревана. Это вызвало необходимость расширения города в пригородные районы, застраивания их новыми жилыми домами, которые стали существенно отличаться от многоквартирных высокоэтажных зданий. С 2015 года в пригородах Еревана были построены ряд жилых кварталов, по своей концепции похожих на европейские и американские коттеджные поселки, или таунхаусы. Сейчас в Ереване ситуация такова, что назрела необходимость пересмотра градостроительной концепции города, учитывающей активное городское строительство.

Ключевые слова: Ереван, новостройки, градостроительство, архитектура, жилые кварталы

\section{New Residential Compounds in Yerevan}

M. Harutyunyan, Institute of Arts, Yerevan, The Republic of Armenia

The large-scale work on the construction of residential buildings, which began in 2010 in Yerevan, has gradually moved to the suburbs of Yerevan.

After the independence of Armenia, the construction of apartment buildings gave a new breath to both urban planning and the economy of Armenia, but at the same time violated the urban planning and architectural environment of Yerevan. Therefore, it became necessary to develop new residential areas in the suburban districts of Yerevan, which began to differ significantly from multi-apartment high-rise buildings. Since 2015, a number of residential areas have been built in the suburbs of Yerevan, which in their concept were similar to European and American cottage villages or townhouses. In the near future, there will be a need to revise the urban planning concept of Yerevan, since the fact is that soon several compounds will be more actively built.

Keywords: Yerevan, new buildings, urban planning, architecture, residential areas

В конце XX века изменение общественного строя в бывших советских республиках, в том числе в Армении, привело к многослойной трансформации городской среды.

С 2000-х годов начали меняться архитектурно-строительная и архитектурно-дизайнерская структура Еревана, активно реализовывались не только экономические, но и государственные и частные строительные программы, было построено много жилых общественных зданий, деловых комплексов. Этот период можно считать началом нового этапа развития новой независимой Армении. Необходимо сказать, отношение профессиональной общественности к этому периоду, к изменившемуся облику города неоднозначно: присутствуют как положительные, так и отрицательные точки, например, несмотря на то, что с момента строительства Северного проспекта (рис. 1) и сформированной им городской среды, мнения специалистов на его счёт до сих пор сильно разнятся, но ни в коем случае нельзя отрицать тот факт, что Северный проспект
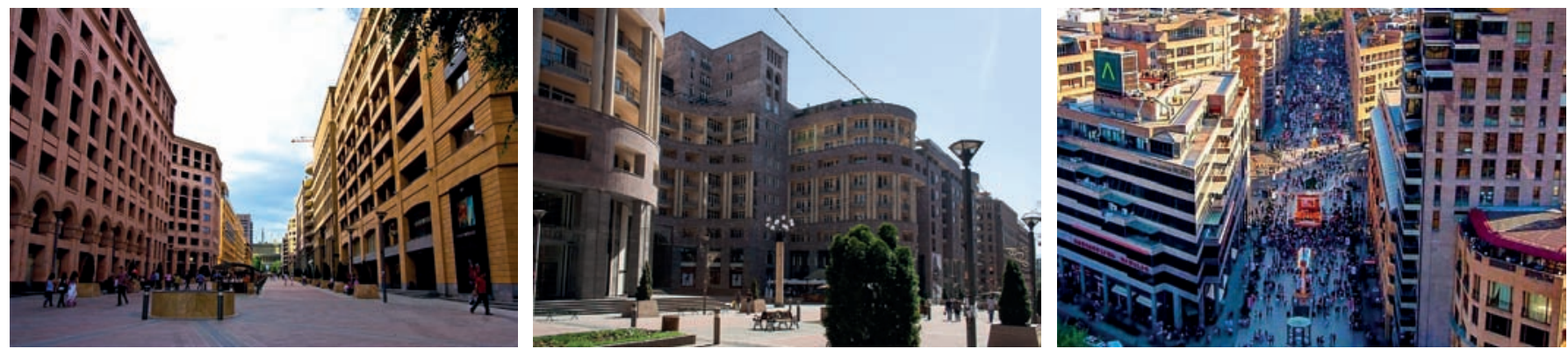

Рис. 1. Северный проспект. Ереван

* Статьи, размещённые в рубрике «Год архитектуры и градостроительства стран СНГ» даны в авторской редакции. 
стал одним из самых оживлённых частей города, любимым как жителями, так и туристами.

В первые десятилетия XXI века в Ереване было построено несколько десятков многоквартирных и многоэтажных зданий, а также торговые и бизнес-центры, другие общественные здания (рис. 2, 3), которые определённым образом изменили архитектурно-градостроительную среду Еревана: целый ряд старых зданий, приставлявших собой историко-культурное наследие, были изменены или демонтированы, уступив свое место новостройкам.

Это масштабное строительство, каким бы положительным оно ни было для экономики страны, подверглось критике со стороны горожан, но и со стороны историков, культурологов и архитекторов, которые обращали внимание на уничтожение культурно-исторических зданий, экологические проблемы, излишне плотную застройку в центральной части города и др. Но при этом нельзя забывать, что как бы эти новостроойки ни искажали архитектурный облик Еревана, они строятся в соответствии с международными стандартами, где потребности жителя XXI века учитываются неизмеримо больше по сравнению с огромным количеством жилых домов, построенных в советское время: там не было подземных парковок, правильно оборудованных игровых площадок, освещение было недостаточное, а также имелся ряд функциональных, эргономических и строительных проблем.

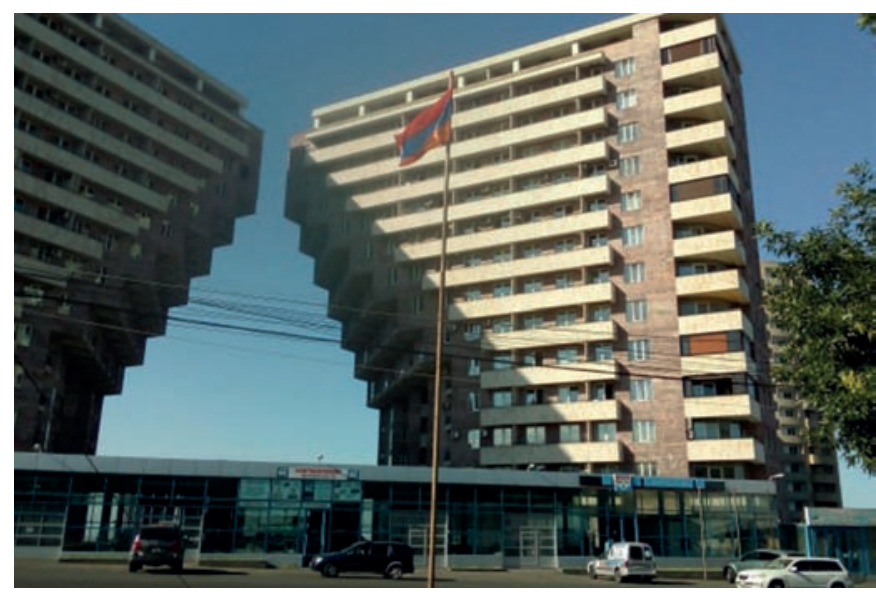

Рис. 2. Жилой комплекс. Улица Н. Заряна, Ереван
Сложившаяся ситуация осложняется ещё и тем, что на протяжении многих лет в независимой Армении не было государственного контроля над существующими и вновь строящимися архитектурными объектами, их дворовыми территориями, в результате чего многие здания лишились зеленых насаждений, оказались окружёнными гаражами, некрасивыми пристройками, часть из них были преобразованы в магазины или другие общественные объекты.

В указанных обстоятельствах ереванцы столкнулись с периодом, когда, с одной стороны, многоквартирные здания, соответствующие международным стандартам, строились в центральных частях города, где неизбежны автомобильные пробки и очень плохая экология, с другой стороны, - неудобные окружённые пристройками многоквартирные дома советского периода, часто - с архитектурными искажениями. Правда, начиная с 2010 года строительство новостроек было перенесено в периферийные районы Еревана.

Были построены новые кварталов с высотной застройкой, среди них «Верацнунд» (рис. 4), «Назарбекян Тауэр», «Ной» (рис. 4) и др.

Новые жилые кварталы, далёкие от центральных районов Еревана, по своей концепции существенно отличаются от многоквартирных. С 2015 года в Ереване им на смену пришли маленькие жилые кварталы, застроенные особняками, таунхаусами или коттеджами. Они настолько

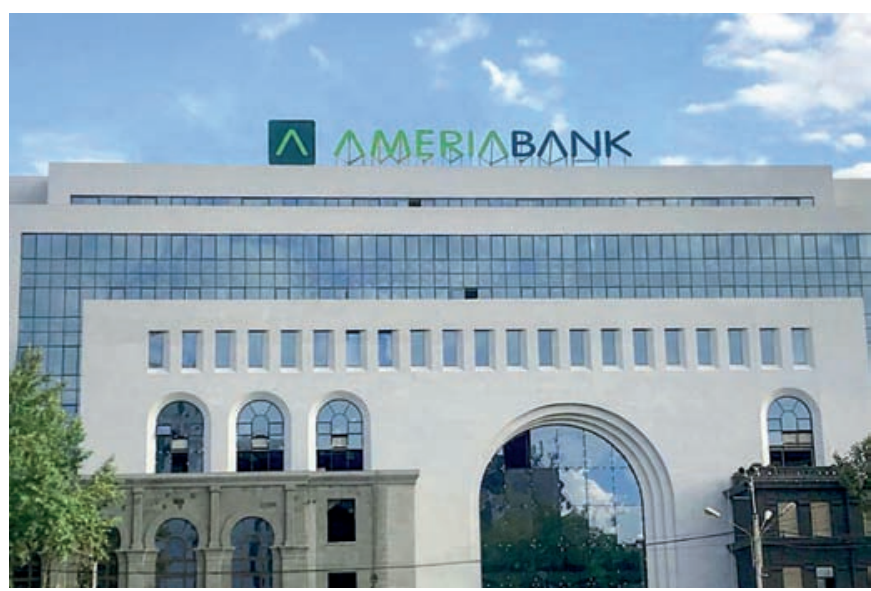

Рис. 3. Бизнес-центр. Улица В. Саргсяна, Ереван

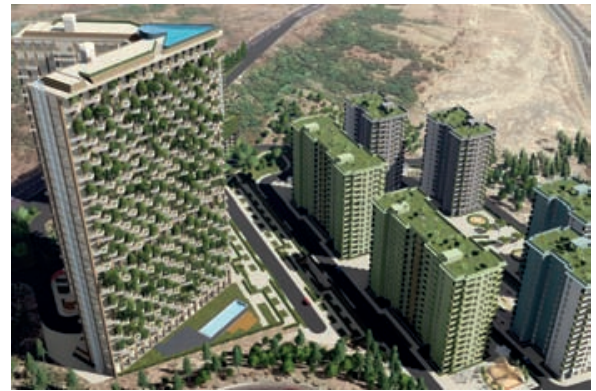

a)

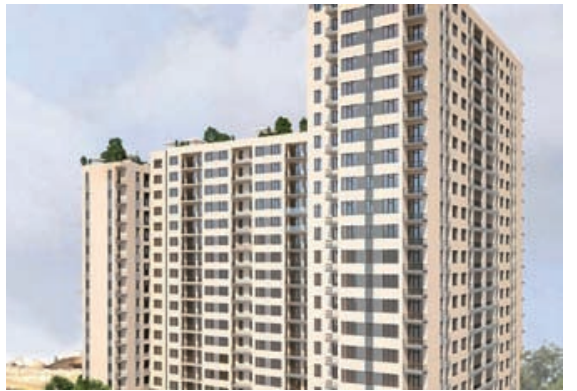

б)

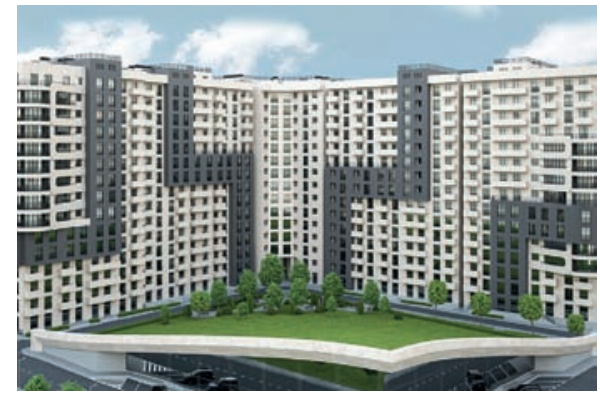

B)

Рис. 4. Новые кварталы Еревана: а) «Верацнунд»; б) «Назарбекян-Тауэр»; в) «Ной» «Верацнунд» 
востребованы среди людей, ищущих квартиры и уклоняющихся от городского шума, что за последние пять лет в Ереване были построены и продолжают строиться десятки жилых кварталов подобного рода.

Первым из новых жилых районов, отличающихся от прежних своим архитектурно-дизайнерским оформлением, средой, освещением, преобладанием зелёных территорий и комфортом, стал квартал «Гарунаван» (рис. 5) в Нор норке (улица Вильнюса). В «Гарунаване» гармонично сочетаются окружающая среда, доступность ближайших торговых центров, транспортная доступность, и в то же время он находится в пригороде, вдали от городского шума. Коттеджи, построенные рядом друг с другом, имеют прекрасный вид на гору Арарат, у каждого владельца есть небольшой сад, автостоянка. Они по своей архитектурнодизайнерской композиции очень похожи на маленькие американские особняки.

В 2020 году также завершилось строительство жилого квартала «Гарунаван 2», который находится в высокогорной зоне общины Нор Норк, где загрязнение воздуха минимально. Квартал «Гарунаван 2» (рис. 6 а) представляет закрытую огороженную территорию с шестью

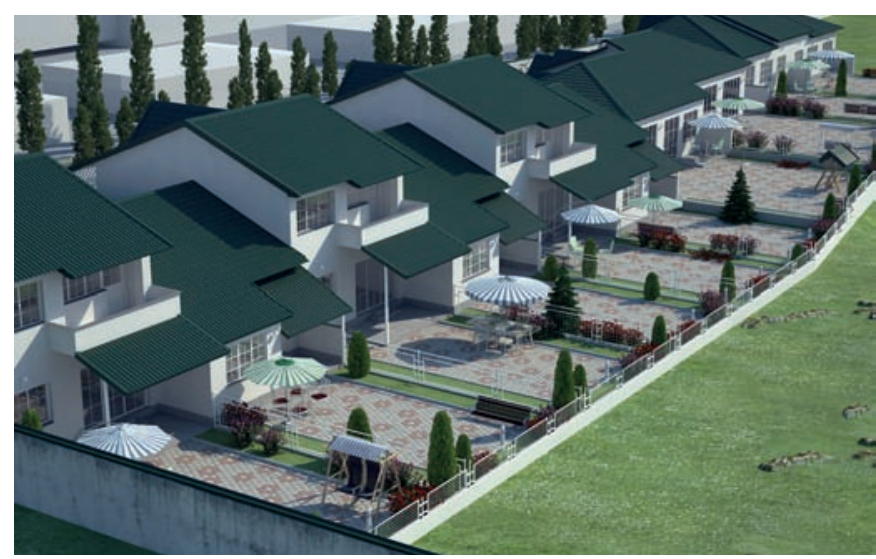

Рис. 5. «Гарунаван» - новый квартал в Нор норке. Улица Вильнюса, Ереван

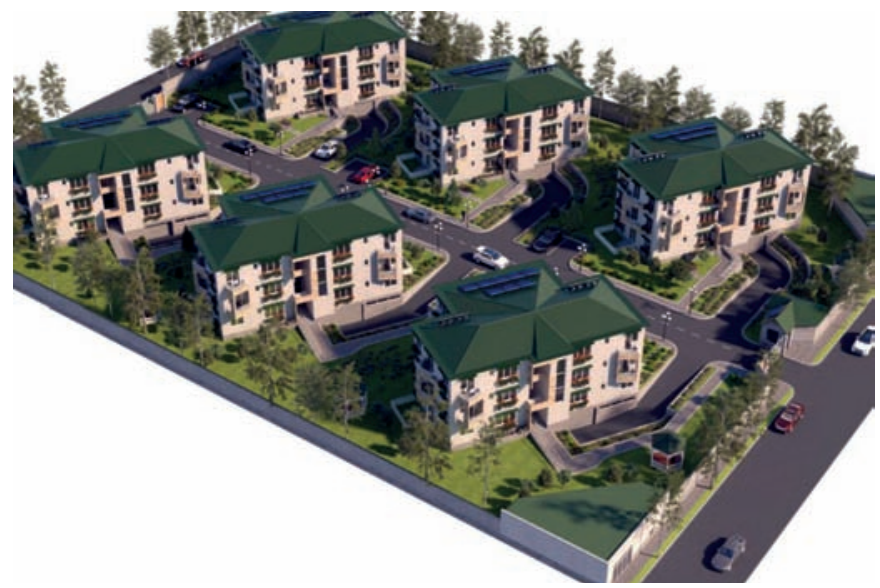

a)

Рис. 6. Кварталы «Гарунаван-2» (а) и «Гарунаван-3» (б). Визуализация. Ереван трёхэтажными зданиями, в каждом здании по девять квартир. Территория покрыта зеленью, безопасна, находится вдали от городского шума. Многие из квартир имеют небольшой сад, на территории установлены павильоны, есть автостоянка. Квартал «Гарунаван 2» придал новый импульс застройке Еревана, это был совершенно новый концепт, который привлёк ряд граждан, так как сочетал комплексный архитектурно-дизайнерский проект квартиры и дачи: квартиры комфортны, обеспечены всем необходимым критериями комфорта, а здания расположены в прохладной и зеленой зоне.

За кварталом «Гарунаван-2» последовал жилой квартал «Гарунаван-3» (рис. 6 б), находящийся в настоящее время в активной стадии строительства. Это трёх-четырёхэтажные дома, многие из квартир в которых имеют прекрасное освещение, вид на гору Арарат, а также просторные террасы. Новые жилые кварталы строятся в пригородных районах Еревана, так как это является требованием будущих покупателей. Граждане хотят жить вдали от центра, где воздух более чистый, территории озеленённая и высокий уровень комфорта.

На рисунке 7 показаны новые кварталы Еревана, построенные, начиная с 2015 года.

Строительство новых жилых кварталы на этом не заканчиваются, оно активно продолжается, и очень скоро новые кварталы выйдут за пределы Еревна. На этапе местных исследований и сбора информации (февральмарт 2020 года) было выяснено, что все новопостроенные жилые кварталы, представленные в исследовании, построены и строятся в соответствии с международными строительными нормами. Эти новопостроенные кварталы придали новое дыхание архитектуре окрестностей Еревана в отличие от однообразных многоквартирных домов, которые были построены очень быстро, но иногда и без учёта фактора окружающей среды.

Как бы пафосно это не звучало, но для формирования современной городской среды необходимо разработать,

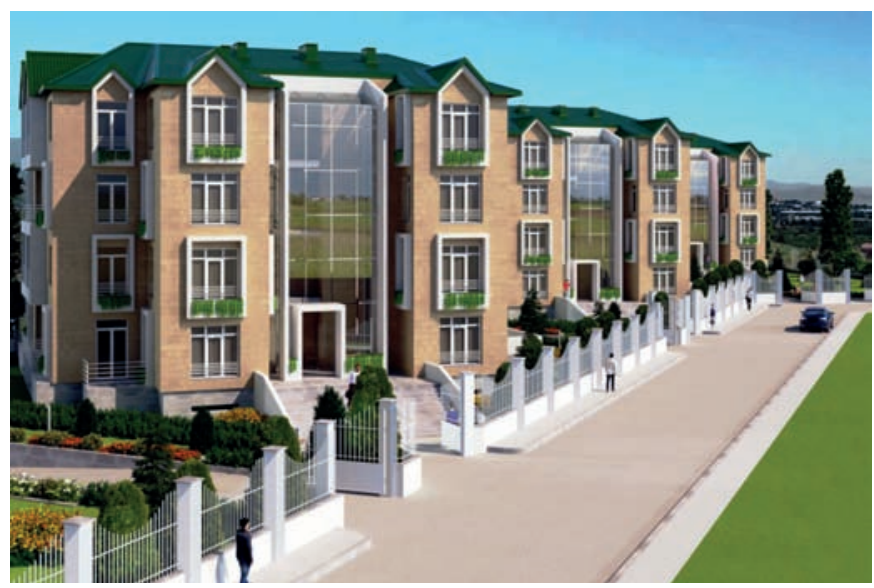

б) 
в которой будут учтены также все вопросы, связанные с архитектурнор-дизайнерскими проблемами, комфотом, озеленением, коммуникациями и пр. Эти проблемы, являющиеся частью градостроительства и городской архитектуры, должны решаться комплексно. Главное проблема зонирования проектов. Настало время, чтобы и государство, и застройщик, и будущий житель стали более инициативными и участвовали на всех этапах решения этих проблем, в том числе и законодательных.

А как должны быть решены подобные проектные задачи?

Конечно, как уже было отмечено, строящиеся новые жилые кварталы должны быть построены в совершенно новых зонах, вдали от каких-либо прежних или старых зданий и других строений, устанавливающих связь с ними; они со временем должны объединиться и оформить местную среду, связанную с другими городскими и административными территориями. Желательно также, чтобы они были разработаны и рассмотрены всеми заинтересованными сторонами. Исследованиями также выяснено, что до сих пор все частные мнения не имели особого значения для принятия единственного решения. Необходимо учитывать также и тот факт, что в последние годы армянская диаспора (а она в три раза больше населения Армении) активно покупает квартиры на родине, и этот процесс также стимулирует строительство новых зданий и кварталов.

Печально, но даже сейчас в государственном масштабе нет единого мнения - сохранять старое или нет, а если да, то как?

К сожалению, в градостроительстве отсутствует также какое-либо единое мнение относительно того, как противостоять «тяжёлым ударам» новостроек, чтобы сохранить старую архитектурно-дизайнерскую структуру города. Мы считаем, что «разрушение всего» - это не выход! Современное градостроительство предлагает множество решений,

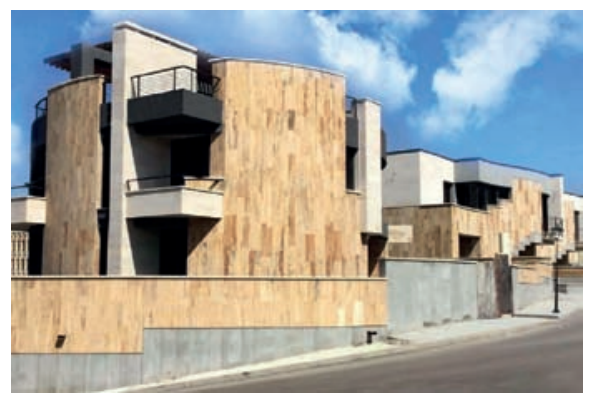

a)

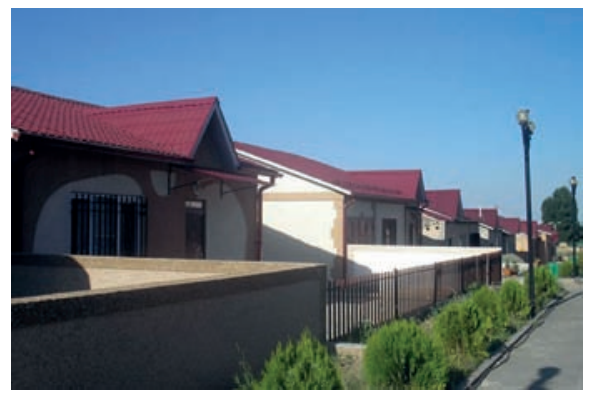

2)

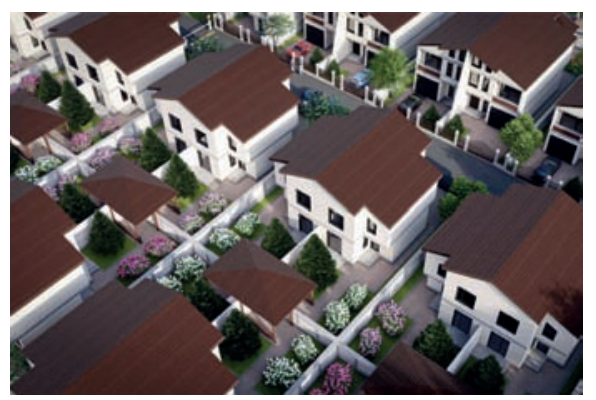

ж)

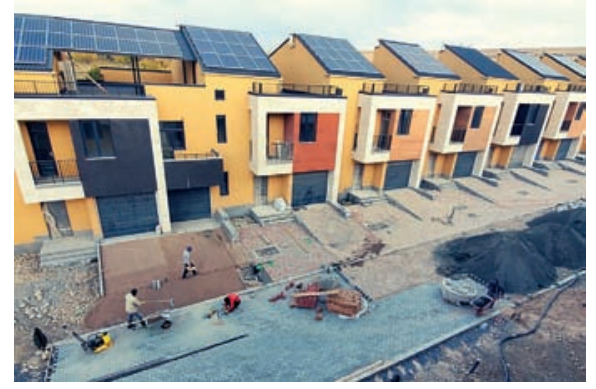

б)

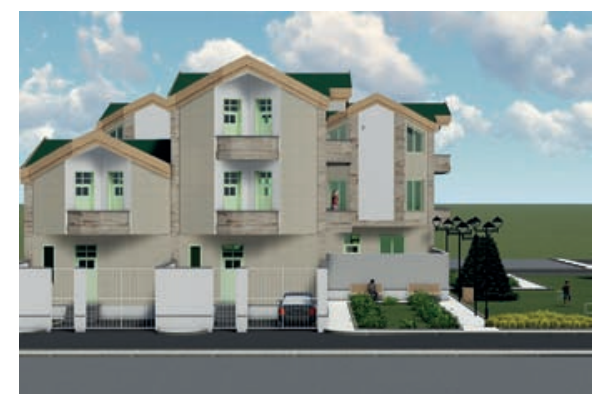

d)

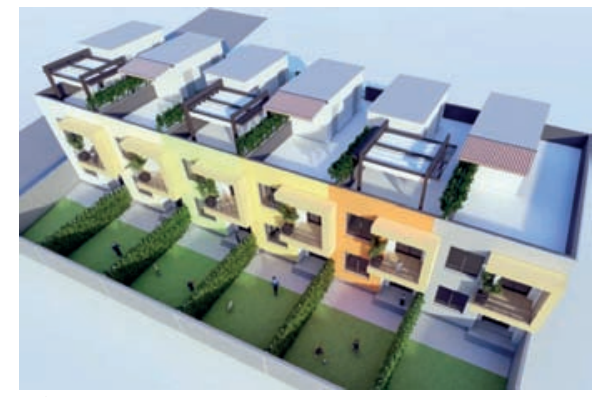

3)

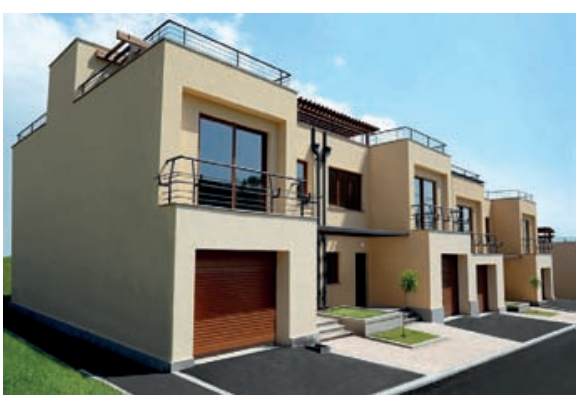

B)

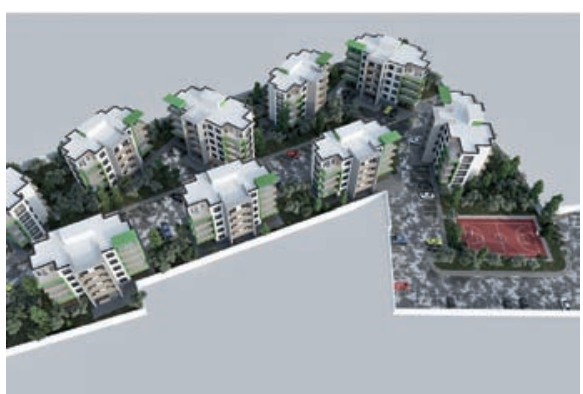

e)

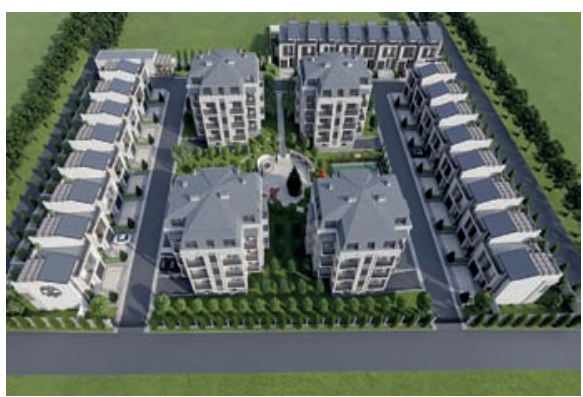

u)

Рис. 7. Новые квартала Еревана: а) «Хай Парк» (High Park»). Улица Ачаряна; б) «Солар Сити» (Solar City»). Административная община Аван; в) «Ван». Егвардское шоссе; г) «Сирох (ртер» (дачный участок Дзорахпюр, близ Еревана); д) «Ареви Тун». Ачапняк, квартал Г1; е) «Гринвилл» (Green Ville). Район Давташен; ж) «гарден Хаус» («Garden House». Aдминистративный район Ачапняк; 3) «Фэйри Лэнд» (Fairy Land). Административный район Аван; и) «Смарт-Сuти» (Smart City). Улица Багреванда 
самым важным из которых можно считать строительство новых городов, которые существенно изменят концепции строящихся зданий. Они больше не будут мешать соседним старым зданиям или отрицательно влиять на историкокультурное наследие древних территорий, а коренным образом изменят градостроительную среду Армении и расширят жилые территории. Армения - маленькая и горная страна, однако здесь много пустынных и неиспользуемых территории с ровной поверхностью, где можно создать прекрасную городскую и модернизированную среду.

Арутюнян Мартин Варданович (Ереван, Республика Армения). Кандидат искусствоведения, доцент. Старший научный сотрудник Института Искусств Национальной академии наук Армении (Армения, Ереван 0019, проспект Баграмяна 24 Г. Институт Искусств). Эл. почта: martinharutyunyan@hotmail.com.

Harutyunyan Martin V. (Yerevan, Republic of Armenia). Candidate of Art History, Associate Professor. Senior Researcher at the Institute of Arts of the National Academy of Sciences of the Republic of Armenia (24g Marshall Baghramian Ave., Yerevan 0019, Republic of Armenia. Institute of Arts). E-mail: martinharutyunyan@hotmail.com. 